\title{
“COMO ENCADEAR A VIDA DEPOIS DISSO?”: MEMÓRIA E ESQUECIMENTO EM NO EXÍLIO, DE ELISA LISPECTOR
}

\author{
Patrícia Resende Pereira ${ }^{1}$
}

Resumo: Neste artigo, procura-se investigar a maneira como o trauma se faz presente no romance No exílio, escrito por Elisa Lispector e publicado em 1948. A obra tem como protagonista Lizza, uma garota que precisa fugir da Rússia, sua terra natal, ao lado da família, em razão dos violentos ataques conduzidos pelos pogroms contra os judeus, durante a Revolução de Outubro de 1917. Depois de passar por diversos vilarejos da Europa, Lizza e sua família conseguem chegar ao Brasil, mas, ao contrário do que se esperava, a personagem central continua vivendo o trauma. Assim sendo, neste trabalho, investigar-se-á, tendo como base a noção de memória coletiva, a maneira como Lizza e sua família conseguem manter os costumes e as tradições do povo judeu, enquanto fogem dos ataques dos pogroms e como a protagonista, já no Brasil, passa a viver o trauma, ainda que esteja em segurança, longe do perigo vivido.

Palavras-chave: No exílio; Elisa Lispector; memória coletiva; trauma.

Abstract: The purpose of this article is to investigate how the trauma is present in the novel No exílio, written by Elisa Lispector and published in 1948. On the book, Lizza and her family needs to escape from Russia because of violent attacks conducted by pogroms against the Jews during the October Revolution of 1917. After going through many villages of Europe, Lizza can get to Brazil but, contrary to what was expected, the central character is still living the trauma. This article has the purpose to investigate, based on the notion of collective memory, how Lizza is able to maintain the customs and the Jewish people traditions while fleeing pogroms attacks and how the protagonist, already in Brazil, starts to live the trauma, although it is safely away from the danger lived.

Keywords: No exílio; Elisa Lispector; collective memory; trauma.

${ }^{1}$ Doutoranda em Literaturas Modernas e Contemporâneas junto do Programa de PósGraduação em Estudos Literários, da Universidade Federal de Minas Gerais (UFMG). É Bolsista do CNPq. E-mail: patriciarpereira@gmail.com. 


\section{Introdução}

Não adiantava fugir, se não podia libertar-se de si mesma e dos fantasmas que continuariam a rondar em torno dela.

(Elisa Lispector, em No exílio, 2014, p. 190)

Em certo momento de No exílio, da escritora Elisa Lispector, a protagonista Lizza, após o término da Segunda Guerra Mundial, se pergunta se seria possível viver como se nada tivesse acontecido. Ao imaginar como seria esse mundo, a personagem, que, ao lado da família, precisou fugir de sua terra natal em razão da perseguição aos judeus, conclui: "Paz - ainda repetia -, paz, esquecimento." (LISPECTOR, 2014, p. 190). No entanto, logo depois, a moça se dá conta de que nada poderia ser feito, pois "não adiantava fugir, se não podia libertar-se de si mesma e dos fantasmas que continuariam a rondar em torno dela" (LISPECTOR, 2014, p. 193).

A afirmativa de Lizza em muito pode se relacionar à situação daqueles que viveram a situação do trauma. Como destaca a estudiosa Valéria de Marco (2004), ao discutir sobre o conceito de catástrofe, na tentativa de refletir sobre a Shoah ${ }^{2}$, por vezes, se pensa em tragédia, tendo em vista que, na teoria da literatura, o termo "catástrofe" pode se ligar à descrição da tragédia. Contudo, para Marco (2004, p. 54), no âmbito da Shoah, tal decisão seria um engano, já que a "matéria da tragédia ${ }^{3}$ não se confunde com a do testemunho". Isso porque, como acredita a pesquisadora, a paz retorna ao universo da tragédia depois que o problema é solucionado e não mais os personagens precisam conviver com os transtornos causados por aqueles que perturbaram a tranquilidade. Já na matéria do testemunho, a harmonia perdida não será

\footnotetext{
${ }^{2}$ Neste trabalho, usa-se o termo Shoah, devastação em hebraico, para se referir ao genocídio promovido nos campos de concentração, ao invés de Holocausto, como popularmente é conhecido tal acontecimento da história mundial.

${ }^{3}$ Pensa-se que a autora esteja se referindo especificamente à tragédia grega. Como exemplo, é possível citar a tragédia de Édipo Rei, de Sófocles, na qual, apenas depois que o personagem-título descobre ser ele mesmo o assassino do Rei Laio, seu pai, a praga que assola o reinado cessa, pois agora o crime foi solucionado e o responsável por ele, punido.
} 
restituída, ainda que os conflitos estejam aparentemente solucionados, como acontece, por exemplo, com o fim da guerra.

Em razão disso, percebe-se que esse princípio do testemunho pode ser verificado em No exílio. Na obra, Lizza, então com sete anos de idade, junto da família, precisa fugir da Rússia, quando, em razão da Revolução de Outubro de $1917^{4}$, o povo judeu passa a ser perseguido e morto pelos violentos ataques, chamados de pogroms. Para se proteger, a família precisa enfrentar uma longa e difícil travessia pela Europa até conseguir, finalmente, chegar ao Brasil, onde tentam reconstruir a vida. Todavia, conseguir viver, nas palavras da narradora, "normalmente", não parece tão simples quanto à primeira vista a palavra sugere.

Assim sendo, para este trabalho, investigar-se-á a maneira como Lizza tenta lidar com o trauma proporcionado pelos conflitos com os quais se viu envolvida, ainda criança na Rússia, com a fuga da família, e as marcas provocadas pelo trauma, influenciando toda a sua vida. Para tanto, este artigo será dividido em duas partes: na primeira, discutir-se-á o conceito de memória coletiva, tendo em vista que se trata do envolvimento de todo um povo nos conflitos, e o trauma vivenciado em razão dos acontecimentos na Rússia; enquanto a segunda se concentrará na chegada da família ao Brasil e a maneira como Lizza ${ }^{5}$ vive o trauma, culminando em uma crise de depressão.

\footnotetext{
${ }^{4} \mathrm{Na}$ Revolução de Outubro de 1917, na Rússia, Vladimir Lenin, ao lado dos bolcheviques, dão um golpe de Estado para assumir o poder e implantar o regime comunista.

${ }^{5}$ Sabe-se que No exílio é a obra mais autobiográfica de Elisa Lispector, algo comprovado pelo próprio texto da orelha do livro, escrito pela crítica Bella Jozef: "Em No exílio, o mais autobiográfico de seus romances [...]". Ao lado de sua família, incluindo uma recém-nascida Clarice Lispector, Elisa saiu da Ucrânia para fugir da perseguição antissemita proveniente da Revolução Comunista, da mesma maneira como faz Lizza. Contudo, para este artigo, não discutiremos os aspectos concernentes à autobiografia, tendo em vista que nos concentraremos em Lizza e os eventos com os quais se viu envolvida apenas como personagem ficcional.
} 


\section{A fuga da Europa}

Em verdade, nem sempre entendiam a tragédia em toda a sua extensão e significado.

(No exílio, 2004, p. 56)

Para Zilda Kessel (2003), com base no argumento do conhecido estudioso da memória Maurice Halbwachs, a memória coletiva, entendida como a de grupo, tem condições de criar o sentimento de pertencimento a um grupo de passado comum, tendo em vista que eles compartilham, então, as próprias memórias. Corroborando com Kessel (2003), a estudiosa Aleida Assmann (2011), também ao citar Halbwachs, observa que é a existência do grupo que assegura essa memória coletiva. Uma vez dissolvido, os integrantes podem perder em sua memória as lembranças e, com isso, deixarem de se identificar.

A memória coletiva está, como já era de se supor, presente em toda a obra que serve de objeto para este trabalho. Logo no começo do livro, quando a Revolução Comunista provoca uma série de mudanças na Rússia, Pinkhas, pai de Lizza, sabe que, talvez em razão do que escutou ao longo da vida sobre o tratamento dado ao seu povo, os judeus poderão ser injustiçados durante tais transformações no Estado: "Falava-se em liberdade, igualdade, fraternidade, enquanto municipalizavam casas e confiscavam pequenas indústrias. 'Ao judeu', rememorou Pinkhas, 'fizeram sentir, uma vez mais, que era judeu'." (LISPECTOR, 2014, p. 45).

O uso do termo "rememorou" indica que essa não foi a primeira vez que Pinkhas escuta ou diz que o povo judeu fora forçado a se sentir judeu, o que, dentro do contexto do livro, faz com que o leitor pense que se sentir um integrante deste grupo não é algo positivo. Em outro instante, mais uma vez temos a impressão de que a memória coletiva do povo judeu, expressada dentro do universo de No exílio, está marcada por humilhações e muita injustiça, quando Pinkhas afirma que a culpa de todas as tragédias é atribuída ao grupo: "E como faltassem os gêneros, e houvesse alta de preços, epidemias e mortes, novamente ao judeu atribuíram esse fardo de vicissitudes e misérias. 
O judeu era alguém que tinha grandes contas a prestar, oh, se tinha!" (LISPECTOR, 2014, p. 46).

Em razão desse histórico de injustiças e massacres ${ }^{6}$, quando os integrantes do grupo começam a ser mortos, no desenrolar da Revolução Comunista, eles ficam com medo e em silêncio, todos compartilhando o momento de incerteza e de dor:

Pela manhã, os judeus saíam de suas casas para sepultar os mortos e chorar os vivos. Ficavam depois falando com dolorosa sofreguidão, contando casos, tecendo comentários, E ora faziam-no em surdina, com palavras, velas, ora, com crueza e paixão, numa sequência quase interminável. Em verdade, nem sempre compreendiam a tragédia em toda a sua extensão e significado. (LISPECTOR, 2014, p. 47).

Desse modo, conforme destaca Michael Pollak (1989), ainda com os argumentos de Halbwachs como base, a memória coletiva envolve um processo de "negociação" e não apenas a seletividade da memória. Nesse caso, levando em consideração que cada membro do grupo tem a sua própria memória individual, é preciso que ambas "concordem", na ausência de termo melhor, em seu conteúdo.

Para que nossa memória se beneficie da dos outros, não basta que eles nos tragam seus testemunhos: é preciso também que ela não tenha deixado de concordar com suas memórias e que haja suficientes pontos de contato entre ela e as outras para que a lembrança que os outros nos trazem possa ser reconstruída sobre uma base comum (HALBWACHS apud POLLAK, 1989, p. 4)

Pode-se notar, assim, que cada um, dentro do grupo, compartilha a mesma memória, marcado pela exclusão e pelo medo. Esse princípio aparece de modo mais claro no momento em que se percebe que, diante da situação de perigo na qual se viram envolvidas, as pessoas optaram pelo silêncio, em um

\footnotetext{
${ }^{6}$ Em certo instante do livro, somos apresentados a alguns momentos de violência vividos pelos judeus: "Eles viram queimadas e espezinhadas as Escrituras Sagradas, assassinados, ou mutilados os sábios filhos e as castas filhas violentadas" (LISPECTOR, 2014, p. 46).
} 
primeiro momento, para, depois, começarem a conversar de modo mais aberto sobre o tema. Em comum, todos compartilhavam o fato de não entenderem o que estava acontecendo, pois, ao acessarem a memória coletiva, não conseguiam encontrar uma explicação plausível que justificasse os eventos de horror testemunhados.

Todavia, a memória coletiva de um grupo não se resume apenas ao "acervo" de ações sofridas contra ou a favor deles, guardado por cada um e passado adiante para os membros mais jovens. A memória coletiva diz respeito, ainda, à realização de rituais e à crença de todo um grupo, servindo de vínculo para uni-lo. Como comenta Kessel (2003), assim como o cristianismo, o judaísmo "tem na lembrança o foco, na medida em que pauta o presente pela rememoração dos acontecimentos e milagres do passado. $O$ tempo é marcado por comemorações litúrgicas, louvam-se santos e mártires, seus milagres são lembrados em datas práticas." (KESSEL, 2003, p. 2).

Assim, embora esteja atravessando a Europa e em uma situação de risco, a família de Lizza continua fazendo os rituais de seu povo, como indica o instante em que se realiza uma pequenina celebração, improvisada no quarto de uma das aldeias em que se hospedou. Ao não conseguir todo o material necessário, em razão das circunstâncias, a mãe de Lizza lamenta: “- Não pude arranjar nada que servisse de korbanot nem de kharosset. Só consegui raiz amarga para o maror. Aves, vinho, nozes... penso que ninguém mais se lembra o que isso vem a ser." (LISPECTOR, 2014, p. 69). Ainda assim, mesmo sem tudo o que é preciso para possibilitar a cerimônia, a família de Lizza realiza o ritual e tenta ter, mesmo em condições adversas, uma vida de normalidade, dentro do frio quartinho da aldeia.

Nota-se que essa busca de normalidade em um cenário pouco propício para tanto, no meio de uma travessia que parece não ter fim, durante o inverno congelante, pode ser relacionada à atitude das mães no campo de concentração. Ao refletir sobre a representação do silêncio na Shoah, o crítico Renato Lessa (2009) comenta um dos episódios apresentado por Primo Levi em seu já muito conhecido É isto um homem?. Nele, Levi descreve que, mesmo na prisão do Campo de Fossoli, aguardando a transferência para Auschwitz, as mães continuaram a cuidar de seus filhos, lavando-os, alimentando-os, cuidando de suas roupas. Pode-se perceber que o |148| 
comportamento das mães, ao serem "precisas e irreflexivas" (LESSA, 2009, p. 94), relaciona-se com o que é observado em No exílio, tendo em vista que mesmo sem as condições adequadas para tanto, os pais de Lizza fizeram um ritual improvisado, na tentativa de continuar a tradição do povo judeu, além de buscar dar um pouco de normalidade para a vida das filhas pequenas.

Contudo, ainda que os pais tentem simular ali uma vida normal, os horrores do que testemunhou, com o seu olhar de criança, interfere na compreensão de Lizza de tudo a sua volta. No começo dos ataques, a garota fica confusa quando, ao lado da mãe e das irmãs menores, precisa se esconder dentro de uma pequena fábrica de vinagre, conduzida por um casal de judeus, ainda na Rússia. Nesse instante, em razão dos pogroms, os judeus estavam sendo assassinados com brutal violência dentro de suas casas, como relata uma anciã à Marim, mãe de Lizza:

- ... é da casa de rabi Meyer - ajuntou a outra velhinha, retomando o seu choro sem lágrimas. Entrelaçava as mãos e balançava a cabeça de cá para lá, como um pêndulo. - Ai, ai, ai, o que "eles" fizeram! Obrigaram-no a pisar a Torá e vazaram-Ihe os olhos; cortaram-Ihe a língua e as orelhas. $\mathrm{Ai}-$ suspirou dolorosamente -, o que "eles" fizeram. (LISPECTOR, 2014, p. 39)

O relato da senhora alerta a mãe dos ataques promovidos em toda a cidade, o que torna a situação ainda mais alarmante quando, ao voltarem para a sua residência, Marim e as filhas se surpreendem ao ver a casa revirada. Para se protegerem, o grupo procura, sem sucesso, por abrigo, até finalmente encontrarem a pequena fábrica. Enquanto escuta os barulhos de granada e os tiros, Lizza pergunta a si mesma por que, até agora, ninguém apareceu para socorrê-los.

Tinha chegado a cursar a escola, e, por pouco que isso tivesse durado, havia aprendido que o mundo não era só a sua cidade. Havia outras, muitas mais, além de rios e mares, e, agora, ouvindo o tiroteio lá fora, ela se pergunta:

- Que estarão fazendo as pessoas desses outros lugares? Que fazem, que não nos ajudam? Porque não é possível que em toda parte seja como aqui. (LISPECTOR, 2014, p. 42). 
Por meio de sua pergunta, a garota tenta compreender o que está acontecendo, encontrar alguma razão que justifique os ataques contra o seu povo e por que, até aquele instante, ninguém de outro lugar, que possivelmente não concorda com os crimes cometidos, apareceu para socorrê-los. Essa necessidade de perguntar, sem obter uma resposta, o porquê dos acontecimentos pode ser relacionada ao que afirma Lessa (2009) sobre os campos de concentração. Ainda tendo o testemunho de Levi como ponto de partida, o estudioso comenta um episódio em que o químico italiano, ao ver um caramelo de gelo, decide, talvez por instinto, pegar o objeto, que lhe é arrancado das mãos com brutalidade. Diante da atitude inesperada do guarda, Levi pergunta-Ihe: "por quê?", ao que Ihe é respondido "aqui não existe "por quê'." (LEVI apud LESSA, 2009, p. 92).

Ao comentar esse episódio, Lessa (2009, p. 06) conclui: "A passagem exibe algo próximo ao impensável: um mundo onde não há 'por quê'. Um mundo onde não há por que é um domínio no qual narrativas básicas - estórias

- não podem ter lugar. É o próprio princípio da causalidade que está aqui em questão." Pode-se perceber que o mesmo ocorre naquele instante com Lizza, pois a garota se pergunta o motivo pelo qual ninguém apareceu para ajudá-los, como ninguém de outro lugar não consegue achar aquilo absurdo e não se esforça para salvá-los.

\section{Memória e trauma no Brasil}

Em vez disso, é o enovelado de teias de aranha, cinzentas, gosmentas teias de aranha... Sem nexo. Sem sentido, sem princípio nem fim.

(No exílio, 2014, p. 184)

Não conseguir encontrar uma explicação para o que passou parece ser algo que guiará Lizza em seus questionamentos pelo resto de sua vida. Dessa forma, já adulta, vivendo no Brasil, quase trinta anos após os primeiros ataques ao povo judeu na Rússia, a personagem se vê atormentada por uma 
depressão, acompanhada por uma febre incessante. Na tentativa de se recuperar, ela decide ir a uma pequena cidade, na serra. Durante o caminho, ela percebe que se sente à deriva: "Lizza ergue-se do banco e encaminhou-se lentamente para casa. Sentia quebranto de forças e de vontade, e um desejo sobre-humano de anular-se na ausência e no silêncio." (LISPECTOR, 2014, p. 192).

Assim sendo, percebe-se que a moça, embora já segura no Brasil, continua vivendo o trauma, refletindo sobre o passado e, agora, atormentada por ele de modo quase físico, como indica as febres que passa a sentir. Seria, portanto, o que Márcio Seligmann-Silva (2008, p. 69) afirma sobre o trauma: "Mais especificamente, o trauma é caracterizado por ser uma memória de um passado que não passa. O trauma mostra-se, portanto, como o fato psicanalítico prototípico no que concerne à sua estrutura temporal."

Por isso, Lizza permanece sentindo o trauma provocado por seu passado, que, para ela, está presente. Ainda segundo Seligmann-Silva (2008, p. 69), "falando na língua da melancolia, podemos pensar que algo da cena traumática sempre permanece incorporado, como um corpo estranho, dentro do sobrevivente." Portanto, o trauma vivido por Lizza permanece dentro de sua mente, paralisando-a, impedindo que siga a sua vida. Esse estado de paralisia, de não se sentir dona de suas próprias escolhas, provocado pelo trauma, torna-se evidente quando Lizza reflete sobre seus caminhos:

Por que falhei em meus desígnios, por que me deixei levar pelas águas lodosas do rio sem fundo nem margens? Por quê? Ah, poder sentir-se dona de seu destino, vivê-lo plenamente, livremente, como quem corre campinha aberta afora, rasgando o espaço, desafiando a ligeireza do vento, embriagada de luz, alheia à voz tacanha do conter-se, do moderar-se, do seguir utilitariamente a estrada comum, para logo depois ser atirada na vala comum. Em vez disso, é o enovelado de teias de aranha, cinzentas, gosmentas teias de aranha... Sem nexo. Sem sentido, sem princípio nem fim. (LISPECTOR, 2014, p. 184)

É possível perceber pelo trecho em destaque que Lizza se vê em um mundo sem sentido, como se estivesse presa a uma gosmenta teia de aranha, 
sem ser dona de sua própria história, à deriva. Essa impossibilidade de compreensão dos acontecimentos e, mais ainda, de fazer algo com relação a eles, pode ser pensada por meio de uma imagem evocada pelo estudioso Enrique Padrós (1991, p. 80), quando comenta que, para Schacter, a memória é como um "telescópio apontado ao tempo".

Para Lizza, então, seria como se o seu telescópio imaginário estivesse constantemente apontado para o próprio passado, perseguida pela vontade de esquecer e frustrada diante de tal impossibilidade; seduzida pelo desejo de ser livre, mas, com o passar do tempo, cada vez mais presa à teia. Sabe-se que não existe uma forma de escolher quando se deve ou não se lembrar de algum evento. Como constata Seligmann-Silva (2003, p. 61), "defender como Nietzsche o tempo certo para se esquecer e o tempo certo para se lembrar pode levar à ideia inocente de que podemos controlar nossa memória."

Esse controle, então, é impossível de se ter. Não se sabe quando alguma lembrança irá emergir, especialmente quando se trata do trauma, no qual, como já enfatizamos aqui, com base nas considerações de SeligmannSilva (2008), torna presente constantemente o tempo passado. Esse princípio impede o esquecimento. Portanto, enfatiza-se que, para Padrós (1991), ao ter uma ligação direta com o passado, a memória estabelece "uma necessária interação entre o esquecimento (apagamento) e a preservação integral do passado (na verdade, preservação impossível)" (PADRÓS, 1991, p. 80).

Nesse sentido, a incapacidade de Lizza de deixar de viver o trauma começa a afetar a sua saúde física, como indica a longa sequência em que, já adulta, morando no Brasil, passa a ter crises de febre à noite, enquanto é assombrada por lembranças perturbadoras:

As noites, porém, constituíam-se-lhe num tormento cada vez mais difícil de suportar. Os lençóis encharcados pelo suor eram um fundo açude, a insônia queimando como areias escaldantes, a mente povoando-se de espectros, na memória boiando fragmentos de sua vida passada, com os quais lutava como imersa num mar de sargaços: os olhos loucos de Pantaleão, o doido guardador do vinhedo na encosta do hospital de Kichinev, a meter a cabeça pela janela da enfermaria, à noite, para espreitar as meninas. As caminhadas povoadas de terror, nas longas estepes. O rapaz com a ferida na testa, o sangue a escorrer-lhe até os pés. O odor acre de vinagre. As tenebrosas noites no fundo do porão, ouvindo o 
ressoar da metralha. Os silvos das granadas. Os silêncios alucinatórios. A mãe gemendo. (LISPECTOR, 2014, p. 183).

Lizza passa a ser atormentada pelas próprias lembranças de modo que, posteriormente, culminaria em uma paralisia apenas curada após passar um ano e meio em um sanatório ${ }^{7}$. Seria, fazendo as devidas considerações quanto ao conceito, como se Lizza fosse, repentinamente durante a noite, surpreendida pelas memórias involuntárias ${ }^{8}$, aquelas evocadas sem qualquer esforço e que aparecem de modo inesperado. Desse modo, durante a noite, em razão da febre e da depressão, Lizza é tomada por imagens que a perturbam ainda mais, tornando impossível que se possa viver em liberdade, como pretendia.

Destaca-se, mais uma vez, que, em razão da ligação entre o esquecimento e a preservação da memória, Lizza e o pai precisam se mudar de casa quando, após a morte da mãe, acometida por anos por uma enfermidade, eles passam a ser atormentados pela lembrança da mulher, como comprova a passagem: "Tiveram que mudar de casa. De cada vez que passavam pelo quarto que fora o dela, parecia-Ihes que Marim chamava. Ouviam-lhe o pranto, continuavam a presenciar o seu sofrimento." (LISPECTOR, 2014, p. 143). Assim sendo, foi impossível se esquecer de todo o sofrimento pelo qual passou a mãe, sendo preciso mudar de casa para deixar de lembrar. Nesse caso, enfatiza-se que esquecer, para Padrós (1991, p. 84), "pode ser uma opção de restringir ao essencial ou, diferentemente, de ocultar." Escolheu-se esquecer, na tentativa de deixar de viver novamente o sofrimento da mãe.

\footnotetext{
${ }^{7}$ Optou-se em escrever o termo "sanatório" neste trabalho uma vez que é a palavra usada pela autora.

${ }^{8}$ Sobre isso, não se pode deixar de pensar também na memória voluntária e a involuntária, refletida por Harald Weinrich (2001) a partir das considerações do escritor francês Marcel Proust. Enquanto a memória é racionalmente evocada por quem se lembra, a involuntária não se submete aos desejos do indivíduo. "Essa memória não tenta mais invocar lembranças através de um esforço da vontade, e também desiste de assegurá-las contra o esquecimento com toda a sorte de artifícios mais ou menos hábeis" (WEINRICH, 2001, p. 208).
} 
Talvez por isso mesmo, com o passar dos anos, Lizza só se sinta confortável quando está em uma pequena vila na serra, onde encontra refúgio. Depois de passar uns dias na serra, ao voltar para a casa, a protagonista sente como se tivesse acabado o sentimento de libertação: "Acabaram-se demasiado cedo o deslumbramento e o sonho, os mutismos cheios de ventura, ao borbulhar entontecedor da cascata, ao cristalino puro do rio, ao badalar sereno dos sinos, o grande e nunca antes experimentado sentimento de libertação" (LISPECTOR, 2014, p. 172).

$\mathrm{Na}$ serra, percebe-se que a personagem tem condições de se sentir livre, provavelmente longe das lembranças dos eventos do passado e, ainda, distante de Pinkhas, seu pai, que continua interessado em discutir a condição dos judeus na Europa, tornando possível que a filha, em todo momento, relembre a situação de seu povo e as dificuldades enfrentadas por sua família. Assim sendo, na serra a moça pode, finalmente, se sentir livre do peso do seu próprio passado, como se tivesse condições de apontar o seu telescópio imaginário, finalmente, para outro local.

Após a morte do pai, Lizza decide voltar pela segunda vez para a serra. Lá encontra Pece, a louca, uma pobre mulher que, segundo os moradores da região, já chegara da Alemanha mentalmente perturbada. Enquanto caminha, Lizza escuta o discurso da moça:

- Não se pode. Não, não se pode fazer mal a uma pessoa, não se pode humilhar, perseguir. Estou dizendo que não, que não se pode. Paga-se por isto, estou dizendo: paga-se. Ah-ah-ah, eles riem?

Gesticulava e olhava, espantada, as fisionomias indiferentes em seu redor, e recomeçava o monólogo, as palavras saindoIhe duras e ritmadas, como o rufar de um tambor. Eram brados partidos de uma mente ferida, de uma consciência conturbada. (LISPECTOR, 2014, p. 191).

Em sua breve aparição, Pece indica ser uma personagem que vive 0 trauma, da mesma forma como Lizza. Todavia, possivelmente em razão do que viveu na Alemanha, Pece passou a sofrer de distúrbios psíquicos, o que não acontece com Lizza, que, embora padeça de uma severa depressão, precisando internar-se em um sanatório, se recupera da doença já no fim da narrativa: "A vida fora mais forte. Depois de 18 meses de reclusão e de 
tormento, Lizza teve alta. Fez a mala e empreendeu a viagem de retorno." (LISPECTOR, 2014, p. 200). Não se sabe se Pece também se recuperou, tendo em vista que sua aparição é muito breve na história.

De todo modo, quando se reflete sobre Pece, não se pode deixar de pensar que foi ela quem viveu, de fato, o testemunho. Segundo destaca Seligmann-Silva (2008), Levi costumava falar sobre a impossibilidade de se testemunhar, tendo em vista que as testemunhas conseguiram manter-se a certa distância dos eventos, impedindo que tenham sido levadas por completo pelos eventos. Elas tiveram condições, de certa forma, de se resguardar. Para explicar melhor, Seligmann-Silva (2008) recorre ao que diz Levi em seu Os afogados e os sobreviventes, no qual se lê: "Quem o fez não voltou, ou então sua capacidade de observação ficou paralisada pelo sofrimento e pela incompreensão" (LEVI apud SELIGMANN-SILVA, 2008, p. 68). Assim sendo, ao possivelmente perder a razão diante dos eventos da Segunda Guerra, pode-se perceber que Pece testemunhou os acontecimentos em sua plenitude, pois ficou paralisada em razão de tudo o que viu e vivenciou.

Já Lizza, embora atormentada pela depressão e pela febre, consegue recuperar-se da enfermidade. Não se sabe, entretanto, se a personagem teve condições de deixar de viver o trauma, talvez de superá-lo e encontrar, finalmente, a própria liberdade. O fim do livro, tingido com cores otimistas, ao menos revela que a personagem pode ter tido um destino feliz, ou, talvez, condições de nutrir esperança em dias melhores: "Mas o poder da luz é mais forte do que o das trevas. Sob a pesada crosta do egoísmo e da cegueira, pulsava no homem aquela centelha generosa e pura, o lume que lhe incutia intuição e discernimento para orientar-se na larga estrada da vida." (LISPECTOR, 2014, p. 201).

\section{Considerações finais}

Ao término deste trabalho, foi possível notar que No exílio trata da memória coletiva do povo judeu, quando este estava correndo perigo com as mudanças proporcionadas pela Revolução Comunista, na Rússia. Mesmo 
assim, embora esteja vivendo uma situação de risco, a família de Lizza continua realizando os rituais de seu povo, em uma tentativa de preservá-lo, como destaca Kessel (2003), e, ainda, de tentar viver uma rotina normal, tal como constata Lessa (2009), com base nos escritos de Levi. Contudo, diante de tudo o que viu, a protagonista é incapaz de ter uma vida "normal", questionando o porquê de tudo ter acontecido e como ninguém os salvou, em um universo onde, como já enfatiza Levi, não existe "por quê".

Nesse ponto, nota-se que Lizza, embora em segurança no Brasil, continua vivendo o trauma, sendo assombrada por ele a todo o momento, por meio de lembranças evocadas que a tomam de surpresa, como a memória involuntária, e só encontrando a sua liberdade quando decide passar uns dias na serra, afastada do pai e do sofrimento do povo judeu. Todavia, quando precisa retornar para a sua casa, Lizza percebe que está deixando a sua liberdade e, mais uma vez, volta a se sentir presa em uma teia de lembranças, pois o trauma, tal como indica Seligmann-Silva (2008), torna presente o tempo passado. 


\section{REFERÊNCIAS}

ASSMANN, Aleida. Memória funcional e memória acumulativa - Dois modos de recordação. In: ASSMANN, Aleida. Espaço da Recordação: Formas e Transformações da Memória Cultural. Campinas, SP: Editora Unicamp, 2011, pp. 143-158.

KESSEL, Zilda. Memória e memória coletiva. São Paulo: Museu da Pessoa, 2003, pp. 1-6. Disponível em: <http://www.memoriaeducacao.hpg.ig.com.br>. Acesso em: 22 jul. 2009.

LESSA, Renato. O silêncio e sua representação. In: SCHWEIDSON, Edelyn (org.). Memórias e cinzas. São Paulo: Perspectiva, 2009, pp. 83-101. LISPECTOR, Elisa. No exílio. São Paulo: Paz e Terra, 2014, pp. 7-201.

MARCO, Valéria de. A literatura de testemunho e a violência de Estado. Lua Nova - Revista de Cultura e Política, São Paulo, v. 62, n. 62, pp. 45-68, 2004. PADRÓS, Enrique Serra. Usos da memória e do esquecimento na História. Letras, n. 22: Literatura e Autoritarismo, Santa Maria, Rio Grande do Sul, pp. 79-95, jan./jun. 1991.

POLLAK, Michael. Memória, esquecimento e silêncio. Estudos Históricos, v. 2, n.3, Rio de Janeiro, pp. 3-15, 1989.

SELIGMANN-SILVA, Márcio. Narrar o trauma: a questão dos testemunhos de catástrofes históricas. Psicologia Clínica, v. 20, n. 1, Rio de Janeiro, pp. 6582, 2008.

SELIGMANN-SILVA, Márcio. Reflexões sobre a memória, a história e o esquecimento. In: SELIGMANN-SILVA, Márcio (org.). História, memória, literatura: o Testemunho na Era das Catástrofes. Campinas: Editora da Unicamp, 2003, pp. 59-89.

WEINRICH, Harald. Uma poesia da lembrança surgida das profundezas do esquecimento (Proust). In: WEINRICH, Harald. Lete: Arte e crítica do esquecimento. Rio de Janeiro: Civilização Brasileira, 2001, pp. 207-212. 